EXTENDED REPORT

\title{
Evidence for familial aggregation of hand, hip, and spine but not knee osteoarthritis in siblings with multiple joint involvement: the GARP study
}

\author{
N Riyazi, I Meulenbelt, H M Kroon, K H Ronday, M-P Hellio le Graverand, \\ F R Rosendaal, F C Breedveld, P E Slagboom, M Kloppenburg
}

See end of article for authors' affiliations

\section{Correspondence to:} Dr M Kloppenburg, Leiden University Medical Centre, Department of Rheumatology, C4-R, PO Box 9600,2300 RC Leiden, Netherlands; g.kloppenburg@lumc.nl

Accepted 12 August 2004 Published Online First 30 September 2004

\begin{abstract}
Objective: To evaluate whether familial aggregation of osteoarthritis differs by joint site in a sibling pair study (GARP) of patients with osteoarthritis at multiple sites.

Subjects: White Dutch probands aged 40 to 70 years and their siblings with primary osteoarthritis at multiple sites.

Methods: The diagnosis of knee, hip, and spine osteoarthritis was based on a combination of pain or stiffness on most days of the previous month and osteophytes or joint space narrowing on $x$ ray. Hand osteoarthritis was defined by ACR criteria. Odds ratios (OR) were calculated for siblings and probands sharing disease in the same joints.

Results: 191 sibling pairs were included (85\% women; mean age 60 years). In the probands, osteoarthritis was present in spine $(76 \%)$, hands $(77 \%)$, knees $(37 \%)$, and hips $(26 \%)$. The most common combinations in probands were spine-hand $(59 \%)$, spine-knee $(27 \%)$, and hand-knee $(25 \%)$. The OR adjusted for age, sex, and body mass index for siblings to be affected in the same joint sites as the proband were increased in osteoarthritis of the hand (OR=4.4 (95\% confidence interval, 2.0 to 9.5)), hip (OR=3.9 (1.8 to 8.4)), spine $(O R=2.2$ (1.0 to 5.1)), hip-spine $(O R=4.7(2.1$ to 10.4$))$, and hand-hip $(O R=3.4(1.1$ to 10.4$))$. Siblings of probands with osteoarthritis in the knee did not have an increased likelihood of knee osteoarthritis.

Conclusions: In middle aged patients with familial osteoarthritis at multiple sites, familial aggregation of osteoarthritis was most striking for hand and hip but remarkably absent for the knee.
\end{abstract}

O steoarthritis is a debilitating disease of joint cartilage destruction and changes in the adjoining bone margins. The exact pathogenesis remains unknown. Age and sex are strong determinants in all joint groups. For other determinants such as body mass index (BMI) and occupation, the impact differs by joint site. ${ }^{1}$ This suggests the presence of subtypes of osteoarthritis with different mechanisms for different sites. Apart from the role of environmental determinants in this disease, a hereditary basis had already been documented as long ago as the 1940s by Stecher, and was later confirmed and extended by Kellgren et al. ${ }^{23}$ Stecher found a two- to threefold risk of the presence of Heberden's nodes in mothers and sisters of probands with Heberden's nodes. ${ }^{2}$ Kellgren et al found that first degree relatives of probands with generalised osteoarthritis had a twofold increase in the disease compared with population controls. ${ }^{3}$

In several subsequent studies familial aggregation has been reported for hand, ${ }^{2}{ }^{4}$ knee, ${ }^{5}$ and hip osteoarthritis ${ }^{67}$ and disc degeneration. ${ }^{89}$ The majority of studies on hand and knee osteoarthritis have concerned subjects with radiographic rather than symptomatic osteoarthritis, and have focused on the familial clustering of one joint site, while no information was collected on the characteristics of other joints in the same subjects. Studies that investigated the familial aggregation of polyarticular osteoarthritis based on the combination of affected joint sites yielded inconsistent results. Familial aggregations of radiographic osteoarthritis of hand in combination with knee, ${ }^{10}{ }^{11}$ of hand in combination with hip, ${ }^{12}{ }^{13}$ and of hand in combination with disc degeneration ${ }^{8}$ have been reported. The study by Bijkerk et $a l^{8}$ was the only one to include radiographic information at all four sites (hands, knees, hips, and spine) and in that study familial aggregation of hand with knee or hip osteoarthritis could not be confirmed. Heritabilities ranging from $10 \%$ to $70 \%$ have been reported for disease at the various joint sites. ${ }^{5910}$ It is unclear whether the varying heritabilities imply that the genetic contribution to osteoarthritis is joint related or whether it is the result of heterogeneous phenotype definitions and study designs, or different prevalences of acquired risk factors.

In the present study we used a well documented sibling pair study on middle aged patients with symptomatic osteoarthritis, radiographically confirmed and at multiple sites, to investigate the familial aggregation of osteoarthritis at specific joint sites (hands, knees, hips, and spine) and combinations of joint sites.

\section{METHODS}

\section{Patient population}

The study was part of the ongoing GARP (genetics, arthrosis and progression) study. The GARP study is aimed at identifying determinants of osteoarthritis susceptibility and progression. The study is based on sibships of white Dutch ancestry with predominantly symptomatic osteoarthritis at multiple sites.

Abbreviations: ACR, American College of Rheumatology; AUSCAN, Australian/Canadian osteoarthritis hand index; CMC, carpometacarpal; DIP, distal interphalangeal; GARP, genetics, arthrosis and progression (study); IP, interphalangeal; MCP, metacarpo-phalangeal; PIP, proximal interphalangeal; WOMAC, Western Ontario and McMaster Universities osteoarthritis index 
Table 1 Characteristics of probands and siblings with familial osteoarthritis at multiple sites of the 191 sibling pairs included in the GARP study

\begin{tabular}{lll}
\hline Variable & Probands & Siblings \\
\hline Women (n (\%)) & $162(85)$ & $150(79)$ \\
Age (years) (mean (range)) & $59.9(46$ to 76$)$ & $60.6(43$ to 79$)$ \\
BMI (kg/m²) (median (range)) & $26.9(20$ to 46$)$ & $26.2(19$ to 46$)$ \\
Structural abnormalities at multiple sites (n (\%)) & $191(100)$ & $191(100)$ \\
Symptomatic osteoarthritis at multiple sites (n (\%)) & $178(93)$ & $166(87)$ \\
Pain or stiffness at multiple sites (n (\%)) & $185(97)$ & $187(98)$ \\
WOMAC 0-100 (median (range)) & $27.3(0$ to 95$)$ & $18.7(0 \text { to } 88)^{*}$ \\
AUSCAN 0-60 (median (range)) & $19.0(0$ to 59) & $15.0(0 \text { to } 54)^{*}$ \\
\hline *p<0.05, probands v siblings. & & \\
AUSCAN, Australian/Canadian osteoarthritis hand index; BMl, body mass index; WOMAC, Western Ontario \\
and McMaster Universities osteoarthritis index.
\end{tabular}

\section{Recruitment and clinical evaluation}

Patients (probands) aged between 40 to 70 years with symptomatic osteoarthritis in the hands, knees, or hipsdiagnosed by rheumatologists, orthopaedic surgeons, and general practitioners in Leiden, The Hague, Delft, Haarlem, and Amsterdam-were informed of the ongoing study by mail. Interested probands were subsequently sent a mailed questionnaire about demographic data, medical history, symptoms and signs of osteoarthritis, and family history of osteoarthritis. Subsequently probands with osteoarthritis at multiple sites and with a positive family history were requested to introduce a sibling "with joint complaints," who was also sent a questionnaire. After obtaining informed consent, all sibships underwent a physical examination and were assessed by a single medical doctor (NR) at the outpatient clinic. Questionnaires were verified and data were collected on physical functioning and quality of life. The two questionnaires used to assess physical functioning were the Western Ontario and McMaster Universities osteoarthritis index (WOMAC) and the Australian/Canadian osteoarthritis hand index (AUSCAN). These questionnaires contain questions on pain, stiffness, and disability in the lower extremities and the hands, respectively, resulting from day to day activities.

Patients with secondary osteoarthritis and familial syndromes with a Mendelian inheritance pattern were excluded.

Table 2 Frequency of symptomatic osteoarthritis at the various joint sites in the probands and siblings with familial osteoarthritis at multiple sites of the 191 sibling pairs included in the GARP study

\begin{tabular}{lcl}
\hline Joints involved & Probands (\%) & Siblings (\%) \\
\hline $\begin{array}{l}\text { Affected sites with symptomatic osteoarthritis } \\
\text { Hand }\end{array}$ & $148(77)$ & $128(67)^{*}$ \\
DIP, PIP, or CMC1 & $127(66)$ & $113(59)$ \\
DIP & $93(49)$ & $74(39)^{*}$ \\
PIP & $81(42)$ & $66(35)$ \\
CMC1 & $57(30)$ & $47(25)$ \\
Spine & $145(76)$ & $159(83)$ \\
Hip & $49(26)$ & $44(23)$ \\
Knee & $70(37)$ & $60(31)$ \\
& & \\
Combination of sites with symptomatic osteoarthritis $(\%)$ \\
Hand-spine & $112(59)$ & $105(55)$ \\
Hand-knee & $48(25)$ & $34(18)$ \\
Hand-hip & $28(15)$ & $23(12)$ \\
Knee-spine & $51(27)$ & $53(28)$ \\
Hip-spine & $39(20)$ & $39(20)$ \\
Hip-knee & $16(8)$ & $13(7)$ \\
\hline * $<0.05$, probands $v$ siblings. & \\
CMCl, first carpometacarpal joint; DIP, distal interphalangeal joint; PIP, \\
proximal interphalangeal joint.
\end{tabular}

Osteoarthritis developing under the following conditions was considered secondary:

- major congenital or developmental diseases and bone dysplasias;

- major local factors such as severe scoliosis and hypermobility;

- certain metabolic diseases associated with joint disease such as haemochromatosis and Wilson's disease;

- inflammatory joint diseases such as rheumatoid arthritis;

- other bone diseases such as Paget's disease and osteochondritis;

- intra-articular fracture.

Patients with a shortened life expectancy were also excluded. Crystal deposition arthropathies (unless in the case of severe polyarticular gout), and diabetes mellitus or thyroid conditions were not considered to be exclusion criteria.

\section{Diagnosis of osteoarthritis}

Probands and siblings were included in the GARP study with osteoarthritis at multiple joint sites in the hands or with osteoarthritis in two or more of the following joint sites: hand, spine (cervical or lumbar), knee, or hip. Both groups of subjects were required to have symptomatic osteoarthritis (as defined below) in at least one joint site. Subjects with symptomatic osteoarthritis in only one joint site were required to have structural abnormalities in at least one other joint site, defined by the presence of radiographic osteoarthritis in any of the four joints or the presence of two or more Heberden nodes, Bouchard nodes, or squaring of at least one first carpo-metacarpal (CMCl) joint on physical examination.

Symptomatic osteoarthritis in the knee and hip was defined according to the American College of Rheumatology (ACR) recommendations for knee and hip osteoarthritis. ${ }^{14}{ }^{15}$

Knee osteoarthritis was defined as pain or stiffness for most days of the preceding month and osteophytes at the joint margins of the tibiofemoral joint ( $x$ ray spurs).

Hip osteoarthritis was defined as pain or stiffness in the groin and hip region on most days of the preceding month in addition to femoral or acetabular osteophytes or axial joint space narrowing on radiography. Prosthetic joints in the hips or knees as a result of end stage osteoarthritis were defined as osteoarthritis in that particular joint.

Spine osteoarthritis (cervical and lumbar) was defined as pain or stiffness in the spine on most days of the preceding month, in addition to a Kellgren-Lawrence score of 2 in at least one disc or one apophyseal joint.

Osteoarthritis in hand joints was defined according to the ACR criteria ${ }^{16}$ as pain or stiffness on most days of the 
Table 3 The odds ratios of site sharing (symptomatic osteoarthritis) in patients with familial osteoarthritis at multiple sites

\begin{tabular}{|c|c|c|c|c|c|}
\hline Osteoarthritis site & & Sibling $\mathrm{OA}_{+}$ & Sibling $\mathrm{OA}_{-}$ & Crude OR $(95 \% \mathrm{Cl})$ & Adjusted OR $(95 \% \mathrm{Cl})$ \\
\hline Hand & $\begin{array}{l}\text { Proband OA+ } \\
\text { Proband OA- }\end{array}$ & $\begin{array}{r}109 \\
19\end{array}$ & $\begin{array}{l}39 \\
24\end{array}$ & $3.5(1.7$ to 7.1$)$ & 4.4 (2.0 to 9.5$)$ \\
\hline DIP & $\begin{array}{l}\text { Proband OA+ } \\
\text { Proband OA- }\end{array}$ & $\begin{array}{l}45 \\
29\end{array}$ & $\begin{array}{l}48 \\
69\end{array}$ & 2.2 (1.2 to 4.0$)$ & $2.3(1.2$ to 4.4$)$ \\
\hline PIP & $\begin{array}{l}\text { Proband OA+ } \\
\text { Proband OA- }\end{array}$ & $\begin{array}{l}35 \\
31\end{array}$ & $\begin{array}{l}46 \\
79\end{array}$ & $1.9(1.1$ to 3.6$)$ & 1.8 (1.0 to 3.4$)$ \\
\hline $\mathrm{CMCl}$ & $\begin{array}{l}\text { Proband OA+ } \\
\text { Proband OA- }\end{array}$ & $\begin{array}{l}21 \\
26\end{array}$ & $\begin{array}{r}36 \\
108\end{array}$ & 2.4 (1.2 to 4.8$)$ & 2.6 (1.2 to 5.4$)$ \\
\hline Spine & $\begin{array}{l}\text { Proband OA+ } \\
\text { Proband OA- }\end{array}$ & $\begin{array}{r}125 \\
34\end{array}$ & $\begin{array}{l}20 \\
12\end{array}$ & $2.2(1.0$ to 5.0$)$ & $2.2(1.0$ to 5.1$)$ \\
\hline Hip & $\begin{array}{l}\text { Proband OA+ } \\
\text { Proband OA- }\end{array}$ & $\begin{array}{l}23 \\
21\end{array}$ & $\begin{array}{r}26 \\
121\end{array}$ & $5.1(2.5$ to 10.6$)$ & $3.9(1.8$ to 8.4$)$ \\
\hline Knee & $\begin{array}{l}\text { Proband OA+ } \\
\text { Proband OA- }\end{array}$ & $\begin{array}{l}23 \\
37\end{array}$ & $\begin{array}{l}47 \\
84\end{array}$ & $1.1(0.6$ to 2.1$)$ & $1.0(0.5$ to 2.0$)$ \\
\hline
\end{tabular}

preceding month in addition to three of the following four criteria: bony swelling of two or more of the 10 selected joints (bilateral distal interphalangeal (DIP) joints $2+3$, bilateral proximal interphalangeal (PIP) joints $2+3$, and CMC1 joints), bony swelling of two or more DIP joints, fewer than three swollen metacarpo-phalangeal (MCP) joints, and deformity of at least one of the 10 selected joints.

A subanalysis was carried out for osteoarthritis in the different hand joints. DIP, PIP (which included the interphalangeal joints), and CMCl osteoarthritis was defined by pain or stiffness on most days of the preceding month at each joint site in addition to a Kellgren-Lawrence score of at least 2 in the corresponding joint site.

\section{Radiographs}

Conventional radiographs of the hands (dorso-volar), knees (posterior-anterior (PA) in weight bearing semiflexed and lateral), hips (PA), lumbar (PA and lateral), and cervical spine (anterior-posterior, lateral, and transbuccal) were obtained from all participants. They were taken in a standard manner with a fixed film focus distance and a fixed joint position. Conventional radiographs of the knees were taken using the fixed flexion radiography, as recommended by Peterfy et al. ${ }^{17}$ All radiographs were taken by a single experienced radiology technician. Conventional radiographs were scored by a single experienced musculoskeletal radiologist (HK) for osteophytes in the knees and hips, and joint space narrowing in the hips. In addition to the hands (DIPs, PIPs, and CMC1), the discs and apophyseal joints of the cervical and lumbar spine, the hips, and the tibiofemoral joints of the knees were also scored according to the Kellgren-Lawrence scale with the help of the original atlas. ${ }^{18}$ This is a five scale scoring system with ascending severity, based on the presence of osteophytes, joint space narrowing, sclerosis, and degenerative cysts. A Kellgren-Lawrence score of $\geqslant 2$ defines osteoarthritis in a particular joint.

Intrareader variability for the different joint sites, scored by the Kellgren-Lawrence method, was assessed: the intraclass correlation coefficient (ICC, with 95\% confidence interval) was for the hands, 0.95 (0.92 to 0.96); for the knees (tibiofemoral), 0.92 (0.86 to 0.96); for the hips, 0.95 (0.92 to 0.98); for the cervical spine (apophyseal and disc), 0.71 (0.52 to 0.84); and for the lumbar spine (apophyseal and disc), 0.67 (0.46 to 0.81$)$. Intrareader variability was based on an examination of 40 radiographs which were selected randomly throughout the duration of the study period and were blinded for any patient characteristics.

\section{Statistical analysis}

Osteoarthritis at each site was dichotomised according to its presence or absence. We calculated odds ratios (OR) for joint disease involving a particular site in the siblings, given the same joint site in the proband. An OR $>1$ in our study indicated that probands and siblings shared disease at the same sites more often than expected from the overall distribution of joint sites with disease. ORs are presented with 95\% confidence intervals (CI), according to Woolf. Unconditional logistic regression analysis was used to adjust for the most important risk factors of osteoarthritis (age, sex, and BMI). The Mann-Whitney $U$ test was used for the comparison of the different types of osteoarthritis in probands and siblings.

\section{RESULTS}

\section{Recruitment}

Of the 1874 probands identified in the various practices, 833 responded $(44 \%)$. Of these 833,521 probands reported a positive family history for osteoarthritis in first degree relatives. Among these, 353 had at least one sibling with joint complaints. Of these siblings, 139 were either unwilling to participate $(\mathrm{n}=92)$ or did not meet the GARP criteria $(n=47)$. This resulted in the recruitment of 214 eligible sibships.

Between August 2000 and March 2003, 212 probands and 224 siblings were screened at the outpatient clinic. After a clinical and radiographic evaluation, 191 probands and 202 siblings met the GARP criteria. If there was more than one affected sibling, the youngest one with osteoarthritis at multiple joint sites was included.

The characteristics of the 191 sibling pairs are shown in table 1 . The majority of the probands and their siblings were female. Age and BMI were similar in probands and siblings. All probands and siblings had structural abnormalities at least two joint sites. There were 178 probands (93\%) and 166 siblings $(87 \%)$ with symptomatic osteoarthritis at multiple 
Table 4 Concordance between probands and siblings for the combination of two affected joint sites with symptomatic osteoarthritis in patients with familial osteoarthritis at multiple sites

\begin{tabular}{|c|c|c|c|c|c|}
\hline Osteoarthritis sites & & Sibling OA+ & Sibling OA- & Crude OR $(95 \% \mathrm{Cl})$ & Adjusted OR $(95 \% \mathrm{Cl})$ \\
\hline Hand-hip & $\begin{array}{l}\text { Proband OA+ } \\
\text { Proband OA- }\end{array}$ & $\begin{array}{r}7 \\
16\end{array}$ & $\begin{array}{r}21 \\
147\end{array}$ & $3.1(1.1$ to 8.3$)$ & $3.4(1.1$ to 10.4$)$ \\
\hline Hand-knee & $\begin{array}{l}\text { Proband OA+ } \\
\text { Proband OA- }\end{array}$ & $\begin{array}{r}10 \\
6 \\
28\end{array}$ & $\begin{array}{r}14 / \\
42 \\
115\end{array}$ & $0.6(0.2$ to 1.5$)$ & $0.6(0.2$ to 1.7$)$ \\
\hline Knee-hip & $\begin{array}{l}\text { Proband OA+ } \\
\text { Proband OA- }\end{array}$ & $\begin{array}{r}2 \\
11\end{array}$ & $\begin{array}{r}14 \\
164\end{array}$ & 2.1 (0.4 to 10.6$)$ & $1.7(0.3$ to 9.2$)$ \\
\hline Knee-spine & $\begin{array}{l}\text { Proband OA+ } \\
\text { Proband OA- }\end{array}$ & $\begin{array}{l}12 \\
41\end{array}$ & $\begin{array}{l}39 \\
99\end{array}$ & $0.7(0.4$ to 1.6$)$ & $0.7(0.3$ to 1.6$)$ \\
\hline Hip-spine & $\begin{array}{l}\text { Proband OA+ } \\
\text { Proband OA- }\end{array}$ & $\begin{array}{l}18 \\
21\end{array}$ & $\begin{array}{r}21 \\
131\end{array}$ & $5.3(2.5$ to 11.7$)$ & $4.7(2.1$ to 10.4$)$ \\
\hline
\end{tabular}

Results are expressed as crude and adjusted odds ratios with $95 \%$ confidence intervals for age, sex, and body mass index in the 191 sibling pairs included in the GARP study.

$\mathrm{Cl}$, confidence interval; GARP, genetics, arthrosis and progression; OAt, with osteoarthritis; $\mathrm{OA}-$, without osteoarthritis; OR, odds ratio.

sites. Ninety seven per cent of the probands and $98 \%$ of the siblings had pain or stiffness at multiple sites. The median WOMAC score and the median AUSCAN score in probandsrepresenting a sum score of pain, stiffness, and disability in, respectively, the hands and lower extremities-were higher in the probands than in the siblings.

\section{Familial aggregation}

Table 2 shows the frequency of symptomatic osteoarthritis at the various joint sites. These were generally equally distributed between probands and siblings, except in the hand joints, which were less often affected in siblings than in probands $(\mathrm{OR}=0.59 \quad(95 \% \mathrm{CI}, 0.4$ to 0.9$))$. Of the 93 probands and siblings with hip osteoarthritis, 38 had a hip prosthesis, 45 had joint space narrowing as well as osteophytes, eight had osteophytes with no joint space narrowing, and only two had joint space narrowing without osteophytes. Eight probands and three siblings had knee prostheses. The three most common combinations of symptomatic osteoarthritis in the probands were the hand joints in combination with the spine (59\%), the knee in combination with the spine $(27 \%)$, and the hip in combination with the spine $(20 \%)$. We found similar results in the siblings.

The odds ratios for site sharing are given in table 3 . When probands had hand osteoarthritis, siblings had an increased risk of having symptomatic osteoarthritis in the hands (crude $\mathrm{OR}=3.5(95 \% \mathrm{CI}, 1.7$ to 7.1$)$; adjusted $\mathrm{OR}=4.4$ (2.0 to 9.5$)$ ) . This was also found for the hips (crude OR $=5.1$ (2.5 to 10.6); adjusted $\mathrm{OR}=3.9$ (1.8 to 8.4$))$ and spine $(\mathrm{OR}=2.2$ ( 1.0 to 5.0)). Adjustment for age, sex, and BMI did not change the estimate for spine osteoarthritis. When the familial aggregation of osteoarthritis in the apophyseal joints was studied separately from disc degeneration, this estimate was not affected. However, when the proband had involvement of the knee, the siblings did not have an increased likelihood of knee disease. Concordance was most striking for bilateral hip osteoarthritis: siblings of probands with bilateral hip involvement had an 8.1-fold increased risk of also having hip osteoarthritis (crude OR $=8.1$ (95\% CI, 3.1 to 21.0 ); adjusted $\mathrm{OR}=6.9$ (2.6 to 18.7$)$ ). Restriction to female sibling pairs $(n=254)$ produced similar results. Further, when analysis was restricted to the 156 probands and siblings with symptomatic osteoarthritis at multiple sites, the estimates were not materially affected. Additional adjustment in site sharing for exposure to jobs entailing strenuous physical labour did not affect the results.

Table 4 shows the concordance between probands and siblings for the combination of two affected joint sites with symptomatic osteoarthritis. Concordance was highest for the combination of hip-spine, followed by hand-hip. Siblings of probands with osteoarthritis in the hips in combination with the spine had a fivefold increase of having osteoarthritis at the same joint sites (crude OR $=5.3$ (95\% CI, 2.5 to 11.7 ), adjusted $\mathrm{OR}=4.7$ (2.1 to 10.4$)$ ). Siblings of probands with osteoarthritis in the hips in combination with the hands had a threefold increase of having osteoarthritis at the same sites (crude OR $=3.1$ (1.1 to 8.3), adjusted OR $=3.4(1.1$ to 10.4$)$ ).

\section{DISCUSSION}

Among middle aged patients with familial osteoarthritis at multiple sites, siblings tended to be affected at the same joint sites, particularly for osteoarthritis in the hips, hands, and spine but not in the knees.

In the present study, in a patient population with predominantly symptomatic osteoarthritis at multiple sites the familial aggregation was most prominent for hip and hand osteoarthritis. Familial aggregation of hip osteoarthritis has been suggested in other studies, but not in the context of osteoarthritis at multiple sites. In most of these studies, the hip was the only joint site under investigation. Four studies have examined the prevalence of osteoarthritis among relatives of cases who had undergone total hip replacement surgery, a surrogate for severe disease. Lindberg ${ }^{19}$ showed that the frequency of radiological osteoarthritis among siblings of 184 probands was twice as high as in the general population. Chitnavis et al ${ }^{20}$ found a slight increase in a recalled diagnosis of hip osteoarthritis among relatives of 402 probands undergoing total hip replacement surgery compared with controls. Lanyon et al ${ }^{6}$ found a fourfold risk for hip osteoarthritis among siblings of 398 probands with total hip replacement surgery compared with population based controls. Ingvarsson et al ${ }^{21}$ found that siblings of 2713 probands who had undergone total hip replacement surgery for hip osteoarthritis were three times more likely to require such surgery than matched population controls. Data on the familial aggregation for radiographic osteoarthritis are less consistent. MacGregor et $a l^{7}$ found, in a twin study, that genetic factors make a substantial contribution (up to $60 \%$ of the total variance) to radiographic hip osteoarthritis. In the other study investigating radiological osteoarthritis at multiple sites, by Bijkerk et al, ${ }^{8}$ no significant genetic effect was found for radiological hip osteoarthritis in siblings of 118 probands with osteoarthritis at multiple sites, drawn from a random population of 1583 individuals. It should be noted, however, that in the study by Bijkerk et al the number of subjects with hip osteoarthritis was too small to measure heritability accurately.

It is unlikely that the familial aggregation of hip osteoarthritis in the present study can be attributed to 
developmental abnormalities such as dysplasia, as the majority of patients had complaints of osteoarthritis at multiple sites, and great care was taken to exclude patients with possible secondary osteoarthritis (by excluding all patients with intra-articular fractures and those with dysplasia of the hips).

The influence of hereditary factors in the hand has been reported consistently in various studies..$^{2-4} 1011$ Our results confirm these findings. When the separate hand joints are examined, our data are in agreement with the study by Jonsson et al in 2919 patients with hand osteoarthritis, who found a genetic influence in the interphalangeal joints as well as in the first carpo-metacarpal joint.

The familial aggregation of osteoarthritis in the apophyseal joints of the spine has not been studied before. In GARP, diagnosis of spine osteoarthritis was based on the presence of osteoarthritis in the apophyseal joints or the presence of disc degeneration in combination with symptoms. The inclusion of disc degeneration in the osteoarthritis definition used in GARP was prompted by the finding by Bijkerk et al, ${ }^{8}$ who showed that disc degeneration had a strong familial component. An important genetic influence on variation in disc degeneration was also found by Sambrook et $a l^{9}$ in a magnetic resonance imaging (MRI) study with 154 dizygotic twins.

In contrast to the majority of studies showing significant heritability of radiological characteristics of knee osteoarthritis, either isolated or in combination with hand osteoarthritis, no aggregation of knee osteoarthritis was found in the GARP sibling pairs. ${ }^{5}{ }^{10}{ }^{11}$ Familial aggregation for knee osteoarthritis was first found by Spector et $a^{5}$ in a cohort of female twins, with a heritability of $39 \%$. Two segregation studies, by Hirsch et $a l^{10}$ and Felson et al, ${ }^{11}$ found familial clustering of polyarticular osteoarthritis involving the hand and the knee. There are several possible explanations for the discrepancy between our present findings and the findings in the above studies. The crucial difference between our study and the previous studies is that we focused on symptomatic disease in combination with radiology, rather than radiological findings alone. In GARP, only those patients were included who had osteoarthritis symptoms at multiple sites; therefore familial aspects of isolated knee osteoarthritis would go undetected in our study. The familial aggregation reported by Hirsch et $a l^{10}$ and Felson $e t$ al ${ }^{11}$ may be dominated by the effects in the hands as the analysis was based on the sum score of the affected joints in the hands and knees. The reported heritability values are influenced by the greater number of joints that can be affected in the hands than in the knees. Further, the patello-femoral joints were not included in our study, in contrast to the study by Spector et al, ${ }^{5}$ possibly leading to an underestimation of symptomatic knee osteoarthritis in GARP. The absence of familial influences on knee osteoarthritis compared with other joint sites in GARP may reflect environmental factors. It has been suggested that these play a more important role in the development of knee osteoarthritis than that of the hip or the hand. This is supported by various studies that have reported the strongest association of factors such as BMI and mechanical stress with knee osteoarthritis. ${ }^{22-26}$

In the present study, we found that siblings of probands with osteoarthritis in the combination of spine and hip and hand and hip were at increased risk of developing the disease at similar joint sites. A familial hand-hip clustering has been found before by other investigators. ${ }^{12}{ }^{13}$ We found no familial clustering for hand and knee osteoarthritis, in contrast to the study by Felson et al ${ }^{11}$ and Hirsch et al. ${ }^{10}$ In the population based study by Bijkerk et al, ${ }^{8}$ a significant familial clustering of hand osteoarthritis and disc degeneration in the spine (thoracic and lumbar) was found. We could not confirm those findings. Different case definition and different joint sites in the spine may have contributed to the discrepancy.

The patient population included in the GARP study is one in which symptomatic familial osteoarthritis occurs at multiple sites with a relatively early onset (between the ages of 40 and 70 years). To our knowledge the prevalence of this osteoarthritis phenotype in the population has not been established before. In the Rotterdam population based study, generalised radiological osteoarthritis has been reported to occur in $14 \%$ of the population aged 55 to 65 (Slagboom PE, personal communication). Symptomatic osteoarthritis is in general less frequent than radiological osteoarthritis, so a prevalence of less than $14 \%$ seems realistic. Moreover inclusion criteria in the GARP study also require a familial type of osteoarthritis. Familial osteoarthritis at multiple sites is not representative of general osteoarthritis, and the results from the GARP study may not be generalisable to all osteoarthritis phenotypes. Nevertheless, this phenotype is important as it can provide us with insights in the aetiological determinants of osteoarthritis in general.

The response rate in the present study was $44 \%$. This low rate may be partly attributed to the recruitment procedure used. In order to get in touch with the subjects who met the study criteria, several steps had to be taken. All osteoarthritis patients with hand, knee, or hip involvement were contacted by mail, stating the familial aspect of this study. It is conceivable that patients who did not meet these criteria did not respond. Furthermore the low response rate may also partly reflect the low prevalence of this particular osteoarthritis phenotype in the population. That the overall response rate is not a reflection of the response among subjects who met our criteria is further supported by the higher response rate of $70 \%$ in the siblings.

The question that arises now is whether the selection procedure in GARP might somehow have influenced the familial aggregations found in the present study. We do not believe this to have been the case, as the results in the study would only have been biased if siblings were recruited when they had osteoarthritis at the same site as their probands, which was not the case.

\section{Conclusions}

Our results show joint specificity in the familial aggregation of osteoarthritis in sibling pairs with symptomatic osteoarthritis at multiple joint sites. Within this study population the familial influences are most remarkable for osteoarthritis in the hip and the combination of hip and hand osteoarthritis, and least for osteoarthritis in the knee. In the context of existing knowledge our results indicate that genetic mechanisms may contribute to the development of osteoarthritis phenotypes based on isolated hip osteoarthritis or hip osteoarthritis in the presence of a much more generalised phenotype. It is possible that genetic heterogeneity may underlie these different clinical end points.

\section{ACKNOWLEDGEMENTS}

We would like to acknowledge support of the cooperating hospitals and referring rheumatologists, orthopaedic surgeons, and general practitioners in our region, in random order: Dr L N J E M Coene, department of orthopaedic surgery and Dr H K Ronday, department of rheumatology, Leyenburg Hospital, the Hague; I Speyer and Dr M L Westedt, department of rheumatology, Bronovo Hospital, the Hague; Dr D van Schaardenburg, department of rheumatology, Jan van Breemen Institute, Amsterdam; Dr A J Peeters and Dr D van Zeben, department of rheumatology, Reinier de Graaf Hospital, Delft; Dr E J Langelaan, department of orthopaedic surgery, Rijnland Hospital, Leiderdorp, and Dr Y Groeneveld, general practitioner, associated with the Leiden University Medical Centre.

The Dutch Arthritis Association, the Netherlands Organisation for Scientific Research, and Pfizer Inc, Groton, Connecticut, USA provided generous support for this work. 


\section{Authors' affiliations}

N Riyazi, F C Breedveld, M Kloppenburg, Department of Rheumatology, Leiden University Medical Centre, Leiden, Netherlands

I Meulenbelt, P E Slagboom, Department of Molecular Epidemiology, Leiden University Medical Centre

H M Kroon, Department of Radiology, Leiden University Medical Centre K H Ronday, Department of Rheumatology, Leyenburg Hospital, The Hague, Netherlands

M-P Hellio le Graverand, Pfizer Inc, Groton, Connecticut, USA

F R Rosendaal, Department of Clinical Epidemiology, Leiden University Medical Centre

\section{REFERENCES}

1 Peyron JG. Osteoarthritis. The epidemiologic viewpoint. Clin Orthop 1986;213:13-19.

2 Stecher RM. Heberden's nodes: heredity in hypertrophic arthritis of finger joints. Am J Med Sci 1941;201:801-9.

3 Kellgren JH, Lawrence JS, Bier F. Genetic factors in generalised osteoarthritis. Ann Rheum Dis 1963;22:237-55.

4 Jonsson H, Manolescu I, Stefansson SE, Ingvarsson T, Jonsson $\mathrm{HH}$ Manolescu A, et al. The inheritance of hand osteoarthritis in Iceland. Arthritis Rheum 2003:48:391-5.

5 Spector TD, Cicuttini F, Baker J, Loughlin J, Hart D. Genetic influences on osteoarthritis in women: a twin study. BMJ 1996;312:940-3

6 Lanyon P, Muir K, Doherty S, Doherty M. Assessment of a genetic contribution to osteoarthritis of the hip: sibling study. BMJ 2000;321:1179-83.

7 MacGregor AJ, Antoniades L, Matson M, Andrew T, Spector TD. The genetic contribution to radiographic hip osteoarthritis in women: results of a classic twin study. Arthritis Rheum 2000;43:2410-16.

8 Bïkerk C, Houwing-Duistermaat JJ, Valkenburg HA, Meulenbelt I, Hofman A Breedveld FC, et al. Heritabilities of radiologic osteoarthritis in peripheral joints and of disc degeneration of the spine. Arthritis Rheum 1999;42:1729-35.

9 Sambrook PN, MacGregor AJ, Spector TD. Genetic influences on cervical and lumbar disc degeneration: a magnetic resonance imaging study in twins. Arthritis Rheum 1999:42:366-72.

10 Hirsch R, Lethbridge-Cejku M, Hanson R, Scott WW, Reichle R, Plato CC, et al. Familial aggregation of osteoarthritis: data from the Baltimore Longitudinal Study on Aging. Arthritis Rheum 1998;41:1227-32.

11 Felson DT, Couropmitree NN, Chaisson CE, Hannan MT, Zhang $Y$ McAlindon TE, et al. Evidence for a Mendelian gene in a segregation analysis of generalized radiographic osteoarthritis: the Framingham Study. Arthritis Rheum 1998;41:1064-71
12 Hochberg MC, Lane NE, Pressman AR, Genant HK, Scott JC, Nevitt MC. The association of radiographic changes of osteoarthritis of the hand and hip in elderly women. J Rheumatol 1995;22:2291-4.

13 Roh YS, Dequeker J, Mulier JC. Osteoarthrosis at the hand skeleton in primary osteoarthrosis of the hip and in normal controls. Clin Orthop 1973;90:90-4.

14 Altman R, Asch E, Bloch D, Bole G, Borenstein D, Brandt K, et al. Development of criteria for the classification and reporting of osteoarthritis. Classification of osteoarthritis of the knee. Diagnostic and Therapeutic Criteria Committee of the American Rheumatism Association. Arthritis Rheum 1986;29:1039-49.

15 Altman R, Alarcon G, Appelrouth D, Bloch D, Borenstein D, Brandt K, et al. The American College of Rheumatology criteria for the classification and reporting of osteoarthritis of the hip. Arthritis Rheum 1991;34:505-14.

16 Altman R, Alarcon G, Appelrouth D, Bloch D, Borenstein D, Brandt K, et al. The American College of Rheumatology criteria for the classification and reporting of osteoarthritis of the hand. Arthritis Rheum 1990;33:1601-10.

17 Peterfy C, Li J, Zaim S, Duryea J, Lynch J, Miaux Y, et al. Comparison of fixedflexion positioning with fluoroscopic semi-flexed positioning for quantifying radiographic joint-space width in the knee: test-retest reproducibility. Skel Radiol 2003;32:128-32.

18 Kellgren JH, Lawrence JS. Epidemiology of chronic rheumatism. Philadelphia: FA Davis, 1963.

19 Lindberg $\mathrm{H}$. Prevalence of primary coxarthrosis in siblings of patients with primary coxarthrosis. Clin Orthop 1986;203:273-5.

20 Chitnavis J, Sinsheimer JS, Clipsham K, Loughlin J, Sykes B, Burge PD, et al. Genetic influences in end-stage osteoarthritis. sibling risks of hip and knee replacement for idiopathic osteoarthritis. J Bone Joint Surg Br 1997:79:660-4.

21 Ingvarsson T, Stefansson SE, Hallgrimsdottir IB, Frigge ML, Jonsson $\mathrm{H}$, Gulcher J, et al. The inheritance of hip osteoarthritis in Iceland. Arthritis Rheum 2000;43:2785-92.

22 Manek NJ, Hart D, Spector TD, MacGregor AJ. The association of body mass index and osteoarthritis of the knee joint: an examination of genetic and environmental influences. Arthritis Rheum 2003;48:1024-9.

23 Coggon D, Croff P, Kellingray S, Barrett D, McLaren M, Cooper C. Occupational physical activities and osteoarthritis of the knee. Arthritis Rheum 2000;43:1443-9.

24 McAlindon TE, Wilson PW, Aliabadi P, Weissman B, Felson DT. Level of physical activity and the risk of radiographic and symptomatic knee osteoarthritis in the elderly: the Framingham study. Am J Med 1999; 106:151-7.

25 Hart DJ, Spector TD. The relationship of obesity, fat distribution and osteoarthritis in women in the general population: the Chingford Study. J Rheumatol 1993;20:331-5.

26 Sturmer T, Gunther KP, Brenner H. Obesity, overweight and patterns of osteoarthritis: the Ulm Osteoarthritis Study. J Clin Epidemiol, 2000;53:307-13 